\title{
CONSTRUINDO SENTIDOS SOBRE O CUIDADO EM SAÚDE À LUZ DA HERMENÊUTICA GADAMERIANA
}

\author{
Romano Deluque Júnior ${ }^{1}$ \\ https://orcid.org/0000-0003-0992-8043 \\ Márcio Luís Costa ${ }^{2}$ \\ https://orcid.org/0000-0003-0412-4812
}

http://publicacoes.uor.ed.ao/index.php/sapientiae/

\begin{abstract}
Recebido: 18.02 .2020
Aceito: 30.05 .2020

Publicado: 06.07.2020

\section{RESUMO}

Uma contribuição relevante da hermenêutica de Hans-Georg Gadamer para o tema do cuidado concentra-se sobre uma ótica que vislumbra as subjetividades que permeiam o adoecimento humano. Dentro desta perspectiva hermenêutica, as pessoas, além de seres biológicos, são também sujeitos de sua própria subjetividade, e como tais, vivenciam a experiência do cuidado a partir de suas próprias lentes afetivo-subjetivas. O presente estudo pretende ser um ensaio de discussão teórica, que intenta a construção de uma discussão que gere novos sentidos para o tema do cuidado em saúde à luz da Hermenêutica Filosófica de Hans-Georg Gadamer. Para tal, foram utilizados textos do próprio Gadamer (1997; 2002; 2011), assim como publicações de autores que trabalham a temática a partir do mesmo marco teórico. Para Gadamer (1997), os conhecimentos técnicos são obtidos através do estudo e da experiência, já sua correta aplicabilidade, somente será alcançada através do contato hermenêutico-experiencial junto a outra pessoa. E nesse sentido, o diálogo parece constituir uma dimensão decisiva para o estabelecimento de uma relação de abertura e igualdade. Além disso, a medicina baseada em evidências simplesmente não é, por si só, suficiente para prestar um cuidado atencioso e pautado nas peculiaridades subjetivas humanas.
\end{abstract}

Palavras-chave: Hermenêutica; Saúde; Cuidado.

\section{Construyendo sentidos sobre el cuidado de la salud a la luz de la Hermenéutica Gadameriana.}

\section{RESUMEN}

Una contribución relevante de la hermenéutica de Hans-Georg Gadamer para el tema del cuidado se concentra sobre una óptica que vislumbra las subjetividades que impregnan la enfermedad humana. Dentro de esta perspectiva hermenéutica, las personas, además de seres biológicos, son también sujetos con su propia subjetividad, y como tal, experimentan la experiencia del cuidado a partir desde sus propios lentes afetivo-subjetivos. El presente estudio pretende ser un ensayo de discusión teórica, que intenta la construcción de una discusión que genera nuevos significados para el tema del cuidado de la salud a la luz de la Hermenéutica Filosófica de Hans-Georg Gadamer. Con este fin, se utilizaron textos del propio Gadamer (1997; 2002; 2011), así como publicaciones de autores que trabajan el tema desde el mismo marco teórico. Para Gadamer (1997), el conocimiento técnico se obtiene a través del estudio y la experiencia, ya que su aplicabilidad correcta, solo será alcanzada a través del contacto hermenéutico-experiencial junto a la otra persona. En ese sentido, el diálogo parece constituir una dimensión decisiva para el establecimiento de una relación de apertura e igualdad. Además, la medicina basada en evidencias simplemente no es, por si sola, suficiente para proporcionar un cuidado atento y pautado en las peculiaridades subjetivas humanas.

Palavras clave: Hermenéutica; Salud; Cuidado.

\section{Building senses on bealth care in the light of Gadamerian Hermeneutics.}

\section{ABSTRACT}

A relevant contribution of Hans-Georg Gadamer's hermeneutics to the theme of care is focused on an optic that glimpses the subjectivities that permeate human illness. Within this hermeneutic perspective, people, in addition to biological beings, are also subjects of their own subjectivity, and as such, they experience the experience of care from their own affective-subjective lenses. The present study intends to be an essay of theoretical discussion, which intends to build a discussion that generates new meanings for the theme of health care in the light of Hans-Georg Gadamer's Philosophical Hermeneutics. To this end, texts by Gadamer $(1997 ; 2002 ; 2011)$ will be used, as well as

\footnotetext{
${ }^{1}$ Doutorando em Saúde e Desenvolvimento da Região Centro Oeste pela Universidade Federal de Mato Grosso do Sul - UFMS; Mestre em Psicologia pela Universidade Católica Dom Bosco - UCDB; Psicólogo formado pela Universidade para o Desenvolvimento do Estado e da Região do Pantanal - UNIDERP; Acadêmico de Direito. Pesquisador em temas como: Democracia; Processos Migratórios; Adoecimento Mental; e Preconceito. E-mail: romanodeluque@gmail.com

${ }^{2}$ Doutor e mestre em Filosofia a pela Universidad Nacional Autônoma de México. Especialista em Didática e Metodologia do Ensino Superior e formado em Filosofia pelas Faculdades Unidas Católicas de Mato Grosso (FUCMT). É Professor do Programa de Mestrado e Doutorado em Psicologia da Universidade Católica Dom Bosco (UCDB). Editor responsável pela revista Psicologia e Saúde. E-mail: marcius1962@gmail.com
} 
publications by authors working on the theme from the same theoretical framework. For Gadamer (1997), technical knowledge is obtained through study and experience, since its correct applicability, will only be achieved through hermeneutic-experiential contact with the other person. In this sense, dialogue seems to constitute a decisive dimension for the establishment of a relationship of openness and equality. Furthermore, evidence-based medicine is not, in itself, sufficient to provide attentive care based on human subjective peculiarities.

Keywords: Hermeneutics; Health; Care.

\section{Introdução}

Desde o advento do paradigma biopsicossocial, o estudo dos aspectos biológicos, psíquicos e sociais dos processos de saúde e doença vêm sido, cada vez mais, influenciados por aspectos culturais, antropológicos, econômicos e políticos (Rillo, 2015; Pereira et al., 2011). Tanto é que os aportes mais recentes na história das ciências médicas têm trazido a tona uma nova máxima a ser seguida: a humanização do cuidado e da saúde como forma de se humanizar a relação profissionalpaciente. (Rillo, 2015;2008; Benevides \& Passos, 2005; Ayres, 2005). É portanto, indiscutível que, "no âmbito de qualquer modalidade de atenção em saúde, o cuidado humanizado se configura como um aspecto primordial para uma atenção de qualidade às pessoas" (Barros, Jorge \& Pinto, 2010 p.74). Nesse sentido, humanizar a atenção em saúde significa reconhecer as pessoas que buscam nesses serviços as resoluções de suas demandas, como sujeitos de pleno direito (Ayres, 2005; Fortes \& Martins, 2000).

Humanizar é observar cada paciente em sua individualidade, levando em conta suas necessidades específicas e subjetivas, e ampliando, pragmaticamente o seu exercício de autonomia (Silva \& Ferreira, 2013; Fortes \& Martins, 2000). Na prática, o tema se relaciona com uma diversidade de significados, tais como a oposição à violência institucional; o atendimento médico qualificado, tanto em excelência técnica como em capacidade de acolhimento; o cuidado com as condições de trabalho para com os profissionais da área; bem como a melhora da comunicação entre usuários e serviços (Ayres, 2005). Como se vê, os atravessamentos são variados. Parece oportuno, portanto, proceder à uma discussão a respeito do tema a partir de um olhar que vise à reflexão sobre o cuidado humanizado diante das mais variadas relações que são percebidas no campo da saúde, ou seja, perceber a problemática pelos olhos dos que lá atuam e frequentam, em seus respectivos cotidianos.

Já o vocábulo cuidado é constantemente utilizado, dentro do campo da saúde, para se referir à um conjunto de procedimentos técnicos orientados para o êxito de um determinado tratamento (Silva \& Sena, 2008; Ayres, 2004). A questão pode porém, ser remetida para um outro ponto de vista, no qual o cuidado passaria, simultaneamente, à uma categoria de compreensão filosófica e uma atitude prática frente às necessidades dos pacientes e usuários que demandam os serviços de saúde (Ayres, 2004). Isso significa perceber o tema do cuidado enquanto relacionado à interação entre duas ou mais pessoas onde, a partir dessa interação, visar-se-ia o alívio de um sofrimento e alcance de uma condição de bem estar. Evidentemente, os saberes técnicos devem-se fazer presentes dentro dessa relação dialógica, e assim intentarem na direção dessa mesma finalidade curativa.

A noção de cuidado ainda perpassa pelo entendimento que se possui sobre a saúde. Essa última, por sua vez é comumente construída a partir de um critério negativo, relacionado à doença, adquirindo, geralmente, características causal-controlistas (Ayres, 2007). Isso significa perceber uma pessoa como doente porquê a sua glicemia está acima da média, ou por outro lado, percebêla como saudável pois o seu teste para HIV deu negativo. O fato é que, a partir dos discursos pragmáticos oriundos da vida cotidiana, muitos portadores de HIV se sentem saudáveis, ao ponto que, outras pessoas sem patologia biofisiológica aparente ou manifestada, podem se sentir, definitivamente doentes.

O tema é complexo e aproxima-se de uma visão que contemple o subjetivo e o individualizado no que tange ao ser humano (Caprara, 2003; Schraiber, 1998). Nesse sentido, a subjetividade humana deve servir de apoio para discussões sobre as novas formas de se encarar a saúde e a doença. Humanizar a atenção em saúde seria pois, humanizar o momento terapêutico no qual o profissional da área procede com competência tecnocientífica e humana, com vistas a restaurar a 
saúde do paciente (Bettinelli et al., 2003). Nesse sentido, tanto a compreensão do ser humano, bem como de seus processos de saúde e doença, e ainda, do seu processo de cuidar e de "ser cuidado", estão à exigir uma verdadeira reconstrução de caminhos e valores que foram fragmentados ao longo do tempo (Pessini, 2000).

Por este raciocínio, parece ser correto proceder à uma postura crítica em relação à visão estritamente médico-instrumental de saúde. Ao ponderar a conduta de cuidado a partir de instâncias subjetivas humanas, deseja-se dizer que, emergiria assim, uma tarefa interpretativa no que tange a descobrir qual o melhor cuidado para cada indivíduo de acordo com as suas necessidades subjetivas e individualizadas. Para auxiliar na discussão acerca dessa tarefa, propõese aqui, a utilização da Hermenêutica Filosófica de Hans-Georg Gadamer. Em sua obra Verdade e Método - Traços fundamentais de uma hermenêutica filosófica, Gadamer (1997) traz no núcleo de sua discussão, uma proposta de ruptura para com a mentalidade instrumental-metodológica, e aponta a necessidade de elaborar-se métodos mais apropriados, e por consequência, mais humanos, de realizar melhores e mais autênticos diálogos entre as pessoas.

Entender é, para Gadamer (1997), um processo que atravessa a mente humana, a partir de determinada relação dialógica, que objetiva-se a lançar luz sobre os fenômenos e assim adquirir novos e relevantes entendimentos. Isso significa focar na superação de antigos preconceitos para dar boas vindas ao novo e ao outrora desconhecido. No contexto do cuidado em saúde, isso significaria conhecer melhor o paciente e as suas necessidades, procedendo sempre, numa tarefa de clarificar os significados daquilo que é dito e ouvido, dentro da relação terapêutica. Mais que entender simplesmente aquilo que está sendo dito, o esforço hermenêutico posiciona-se como uma maneira singular de perceber à noção de verdade, ou seja, o mundo particular de cada paciente que demanda, de maneira hipossuficiente, por atenção e cuidado.

A interpretação seria portanto, a única forma de apreender-se a verdadeira natureza do humano, que diga-se, é singular, subjetiva, e dinâmica. Varia portanto, de pessoa para pessoa. Em vista de todo o anterior, o presente estudo pretende ser um ensaio de discussão teórica, que intenta a construção de uma discussão que gere novos sentidos para o tema do cuidado em saúde à luz da Hermenêutica Filosófica de Hans-Georg Gadamer. Para tal, serão utilizados textos do próprio Gadamer (1997; 2002; 2011), assim como publicações de autores que trabalham a temática a partir do mesmo marco teórico.

Para contemplar os presentes objetivos, primeiramente, discutir-se-á a respeito dos novos desafios para o cuidado diante do tema da atenção em saúde, para nessa esteira, poder intentar à identificação de demandas por um cuidado humanizado dentro do pragmatismo que emerge na fenomenalidade cotidiana dos serviços públicos de atenção em saúde. Posteriormente é-se apresentada uma breve explanação conceitual sobre o cuidado e a saúde sobre o ponto de vista da hermenêutica gadameriana, em especial, no que tange à crítica gadameriana sobre os padrões estritamente metodológicos em interpretar os manuais internacionais de doença, que culminam na construção daquilo que Gadamer (2011) define como um "caráter oculto" atuante no significado de saúde. Por último, conduz-se uma discussão onde, os significados e conceitos construídos ao longo das prévias exposições a respeito deste campo temático, são atravessados diante dos entraves pragmáticos que impedem o emergir de um momento assistencial humanizado e cuidadoso. Ainda nesse tópico, sugestões são feitas com o intuito de apontar potenciais caminhos para a superação desses impedimentos.

\section{Novos desafios para o cuidado diante do tema da atenção em saúde}

É no contexto da atenção em saúde que o tema do cuidado ganha proeminência e efetividade. Essa trata-se da sistemática com que atuam as redes de atendimento dentro de determinadas regiões. No Brasil, o tema possui contornos bastante característicos com o Sistema Único de Saúde (SUS), de modo que o princípio doutrinário da integralidade emerge como como articulador dos níveis de complexidade presentes no referido sistema de saúde (Macedo \& Martin, 2014; Brêtas, 2003). Possuir tal princípio como base, significa que a rede de atenção à saúde, na figura de seus 
profissionais atuantes, deve estar apta em responder adequadamente às situações de sofrimento/adoecimento demandadas pelos usuários, de modo articulado e individualizado (Macedo \& Martin, 2014; Schraiber, 1998). Contudo, não é necessário ir muito longe para perceber que a realidade, dentro das unidades de atenção à saúde, não é lá o que delas se espera.

Falta de médicos, longas filas de atendimento, falta de leitos, e desvalorização dos profissionais da área são apenas alguns dos problemas vivenciados diariamente pelos que estão inseridos nesse contexto. Novos desafios consistem, nesse sentido, no desenvolvimento de ações para os serviços de atenção a saúde que visem a substituição das práticas tradicionais, focadas na doença, por práticas embasadas em integralidade, que contemplem a pessoa do paciente como um sujeito de múltiplas dimensões, e como partícipe do processo de cuidado voltado a sua própria saúde (Cavalcante et al., 2011)

Não se pode perder de vista que, nos variados cenários da atenção em saúde, tais como os hospitais, consultórios, clínicas, ou postos de saúde, o ser humano ascende como objeto primaz, e como motivação de existência dessas mesmas instituições, (Minayo, 1988). Nesse contexto, pensar o tema do cuidado de modo à afastá-lo dos referenciais estritamente biomédicos e protocolares, e aliá-lo, por conseguinte, à ética e à humanização, não nos parece um mal caminho. Pode-se inclusive afirmar, que a própria saúde, enquanto ciência, não se motiva à existência, senão para ponderar e refletir sobre o modo com que as relações humanas emergem dentro de um contexto de fragilidades e de resistências.

Uma análise do vocábulo cuidado leva-nos à compreendê-lo como um fenômeno existencial básico (Corbani et al., 2009), de modo que o próprio cuidado existe a priori ao ser humano. Vide por exemplo a importância do cuidado diante do ato do nascimento humano, sem ele, o ser humano definha, perde o sentido e morre. Não existe homem sem que haja também o cuidado, são pois, inerentes entre si, o cuidado porque perde sua razão de ser, o homem porque perde sua humanidade (Brêtas, 2003). Eis que o seguinte questionamento se faz pertinente: [...] se os seres humanos não aprendem a ser seres humanos com outros seres humanos, com quem aprenderão?" (Costa \& Bernardes, 2013 p. 171).

Nesse sentido, o cuidado passaria a ser percebido como um estado primordial e constitutivo do ser, que traz sentido ao ser-no-mundo, ao passo em que proporciona contato e afetação entre dois seres humanos (Gomes et al, 2019; Brêtas, 2003). Sobre o tema, Boff (1999) realça a profunda ecodependência humana para com o seu meio e para com o outro, seríamos portanto, seres carentes e incompletos, e demandaríamos assim, por cuidados durante toda a vida. Tais cuidados seriam, por sua vez, supridos pela própria natureza, pelo contato humano, e pelas interações socioculturais. Deste modo, a disposição para cuidar do outro emergiria a partir de uma posição de perceber o outro como outro, em uma condição mútua de afetações e alteridades que se dá no contato entre duas pessoas (Costa \& Bernardes, 2015). Certamente, um contexto de atravessamentos múltiplos e amplamente dependentes entre si, eis que, a partir desse posicionamento, o cuidado poderia passar a ser pensado sob a ótica da hermenêutica.

Ao tempo em que o cuidado pode proporcionar ao homem superar a sua animalidade na direção da verdadeira humanidade, diferenciando-nos isolamento animal (Corbani, Brêtas \& Matheus, 2009; Brêtas, 2003), a própria existência do ato de cuidar pressupõe um processo de humanização a priori. Cuida-se porque foi-se um dia cuidado, do contrário, a tarefa pouco se sustenta. Pode-se ir além, cuida-se bem pois, se foi bem cuidado, cuida-se mal pois houveram obstáculos para um cuidado afetuoso e humanizado. Há, evidentemente, exceções. A humanidade, em seu sentido estrito e pessoal flerta com a virtude do bom cuidado, e portanto, para se proceder à um cuidado pragmaticamente bom, deve-se primeiro embasá-lo sobre um pensamento e uma conduta humanizada, distante de falsos preconceitos e de rasos entendimentos (Gadamer, 2011; Gadamer, 1997).

Questionar pelo significado da saúde parece ser, não obstante, um bom começo para falar-se em cuidado e humanização. Nesse sentido, um afastamento da coisificação que se impõe, pela própria medicina moderna ao sujeito e à saúde, condiz com um primeiro passo na direção de um 
entendimento primário do ser são e do estar são (Rillo, 2008; Rillo, 2015), que frise-se, se difere do estar curado ou do não estar doente. É claro que a OMS (2006) acerta ao declarar a saúde como um completo estado de bem estar físico, mental e social e não somente a ausência de enfermidade ou invalidez, uma opinião verdadeiramente pungente e adequada à contemporaneidade. Cabem naturalmente, algumas considerações.

O enunciado proposto pela OMS (2006) traz, evidentemente, um sentido existencial a respeito da saúde, e a expressa como um resultado de complexos atravessamentos, sobretudo humanos, que emergem a partir do modo como o ser humano se comunica e compartilha experiências dentro da sua própria realidade. É contudo, universalista e por conseguinte, passível de evolução. O completo estado de bem estar físico, mental e social demanda por relativização, pois quando as ciências médicas precedem à uma evolução conceitual, o fazem de um modo que é, em si mesmo, inacessível (Rillo, 2015; Gadamer, 2011). O enigma consiste no ato de perceber que a saúde, ou o bem estar físico relativiza-se de indivíduo para indivíduo, o mesmo é válido em relação ao que se possui por bem estar mental e social (Valerius, 2003). Relativiza-se pois possui ampla dependência das lentes pelas quais o ser humano observa seu mundo e aqueles a sua volta, ou seja, depende da tarefa hermenêutica imposta a cada um de nós ao ponto em que precisamos significar o mundo e as experiências ao nosso redor (Gadamer, 1997).

Nesse sentido, tornar-se-ia possível perceber a saúde em uma escala pormenorizada, típica das lentes afetivas que possuímos, e sentimos o mundo a nossa volta, e desse modo, o entendimento de cuidado passaria pois, a ser matizado pelas experiências que, a priori, vivenciamos e acumulamos no decorrer de nossas vidas.A discussão sobre como aprimorar o cuidado na atenção em saúde não é recente, porém, ainda pode ser enriquecida pela visada teórica da hermenêutica.

$\mathrm{Na}$ Hermenêutica filosófica proposta por Gadamer (2011), os processos de saúde e doença são remetidos ao conceito de equilíbrio. Este, frise-se, não é somente o homeostático, mas também em sentido originário e hipocrático (Matos \& Silva Júnior, 2017), relacionando-se não só à um fato orgânico-biológico, mas como um processo social (Gadamer, 2002; 2011). A história de vida do indivíduo adquire, a partir dessa mesma perspectiva, papel fundamental junto a construção de uma interpretação a respeito do cuidado. Tais elementos são tratados dentro da sua teoria como tradição e cultura, logo, pensar um hermenêutica para se chegar a um cuidado atencioso e humanizado significa pensar também, antes de mais nada, como aquele homem ou mulher gostaria de ser cuidado. E mais, se gostaria de ser cuidado e quando gostaria de ser cuidado. O processo de cura e adoecimento passaria assim, a transitar na direção de um sentido existencial, pois o resgate da história do paciente é fundamental para se compreender a sua identidade socialmente construída (Matos \& Silva Júnior, 2017; Correia, 2006), bem como a constituição de si mesmo.

Parece que pensar o cuidado a partir da tradição e da cultura presentes no arcabouço psíquico de um mesmo indivíduo significa dar nova roupagem á aquilo que se tem por um cuidado com características de humanização. Diante disso, Assis et al. (2015) argumentam em favor da necessidade dos serviços de saúde em atuarem em intervenções centradas no paciente, estimulando sua autonomia e o seu modo de andar a vida. Trata-se de um cuidado que se humaniza a partir do fato de ser precedido por percepções, nas quais, o homem é um sujeito histórico e de tradições. Uma modalidade de cuidado que passaria a caminhar no caminho da desuniversalização e do egoísmo para caminhar rumo à dignificação da subjetividade individual de cada paciente que, frisese, deve ser encarado como sujeito partícipe de seu próprio tratamento (Gadamer, 2011). Sendo permitido a este paciente, inclusive, manifestar suas opiniões e sentidos a respeito das próprias fragilidades e potenciais situações de saúde e doença (Ayres, 2007). Nesse interim, o médico enquanto ser-capaz-de-fazer passaria a atuar como um favorecedor nesse processo mútuo de afetações e de construções de sentidos distintos (Rillo, 2015).

\section{O cuidado à luz da Hermenêutica Gadameriana}

Em sua obra O Caráter Oculto da Saúde, Gadamer (2011) desenvolve importantes contribuições para o campo de produção de conhecimento e de pesquisas no campo das ciências da saúde. Seus 
aportes consistem numa critica aos padrões estritamente biomédicos de encarar a saúde e o ser humano (Araújo et al., 2012), esse último muitas vezes reduzido à um mero número de prontuário, ou a um padrão dentro de determinada curva estatística (Matos \& Silva Júnior, 2017). Dentro do cuidado em saúde importa, tanto quanto a técnica e o conhecimento profissional, o "querer fazer" responsável diante do paciente (Gadamer, 2011).

Saúde não se relacionaria pois, a padrões estritamente metodológicos em interpretar os manuais internacionais de doença, mas sim à uma abordagem hermenêutica capaz de compreender os significados dos fenômenos humanos, bem como os sentidos que permeiam o mundo da vida desse ser humano (Matos \& Silva Júnior, 2017; Rillo, 2015; Ayres, 2007; Spence; 2001). O cuidado em saúde se relaciona, segundo Gadamer (2002; 2011), aos aspectos existenciais inerentes à aquela pessoa em particular, ou seja, à sua forma originária de ser-no-mundo. Nesse sentido, o próprio cuidado individualiza-se e passa a flertar com o relativo: o que pode ser cuidado para um, pode também ser sentido como uma agressão para outro, e nessa mesma esteira, uma gramática mínima de distanciamento pode ser confundida com uma omissão de cuidado. Como se vê, o tema pede reflexão, e nesse sentido, a hermenêutica gadameriana contribui de maneira pertinente.

Uma das contribuições da hermenêutica gadameriana para o tema do cuidado em saúde reside no ponto em que impele-se, à figura do profissional atuante nesse cuidado, ter de operar observando, além daquilo que deve ser tratado, o homem na totalidade de sua situação de vida (Costa, 2004). Daí, há de se reconhecer que, apesar dos recentes avanços técno-científicos inerentes ao campo da medicina, nem só dessa modalidade de atuação curativa reside o cuidado em saúde. A arte de curar não envolve, portanto, somente o combate à doença, mas inclui a convalescença e o próprio cuidado em saúde, que deve, se dar por vias humanizadas (Gadamer, 1997).

O repensar do cuidado no campo da saúde também emerge na sua obra Verdade e Método, nela, Gadamer (1997) questiona e problematiza o alcance e a validade das experiências científicas, tomando sempre o cuidado de não proceder somente ao lado de um demasiado criticismo que não apresenta caminhos ou soluções. Como sugere o título, o cuidado em saúde não pode ser orientado unicamente pelos critérios de verdade obtidos a partir do referencial proposto pela ciência moderna, a qual, por sua vez, tende à um universalismo do tipo um serve pra todos. Tal percepção de verdade, sempre se constituiu, segundo o autor, a partir dos entendimentos próprios das ciências da natureza.

Os aspectos que compõem a saúde são complexos e articulados, vão desde o reequilíbrio organísmico em seu sentido fisiológico, até a reintrodução do paciente na sua posição na vida cotidiana de outrora (Araújo et al., 2012; Caprara, 2003). Portanto, o cuidado diante de um tratamento deve ser estruturado de modo a ser mais apropriado à realidade do paciente ao qual se dirige, nesse sentido, o diálogo terapêutico emerge com grande relevância. Eis então que a tarefa hermenêutica sobrevem uma vez mais. Assim, interpretar aquilo que é dito pelo paciente é portanto, um pressuposto para o cuidado terapêutico humanizado. A escuta do profissional deve ser, nesse caso, atenciosa e distanciada de seus próprios preconceitos (Spence, 2017; Gadamer, 1997).

Compreender o cuidado dentro de um viés gadameriano significa também ouvir o que o outro, aquele que pede pelo cuidado, tem a dizer. A partir desse contato dialógico entre profissional e paciente, as possibilidades quanto ao uso de recursos técnicos e práticos na restauração da saúde emergiriam aliados à um cuidado mais adequado e eficiente. Assim, por esse raciocínio, mais que a mera parte de um tratamento, o diálogo se apresentaria como a base decisiva de toda atividade médica (Stanga \& Rezer, 2015; Gadamer, 2011), humanizando a relação existente entre o profissional e o paciente. Diante do exposto, há de se chamar a atenção para os delineamentos de demora dentro da relação entre profissional de saúde e paciente. Nesse aspecto, a hermenêutica gadameriana parece orientar para uma forma de gestão do tempo de atendimento, que permita parar e escutar as demandas de cuidado, e assim trazê-las para dentro das estratégias e políticas de atenção em saúde. 
Há contudo, um problema de ordem social. Se a orientação do pensamento gadameriano perpassa pela disposição para o diálogo entre os sujeitos, e a partir das interpretações e entendimentos oriundos desse diálogo emergiria uma fusão de horizontes (Gadamer, 1997), não há como negar, feita uma primeira análise, que esse processo se encontraria afetado pelas relações de poder existentes entre o médico ou profissional da saúde, e o paciente. O que se observa em cenário atual, é que ao paciente resta ouvir, e ao médico ou profissional, resta falar. Tal como um momento patológico do cuidado a partir do ponto de vista hermenêutico, tais relações se mostram cada vez mais comuns, principalmente quando, são vislumbradas a partir de sistemas de atenção à saúde de caráter público. É fato que o cuidado, tal como é percebido nessas esferas de atenção à saúde, em seu sentido técnico-instrumental, encontra-se bastante distante do cuidar em seu sentido mais profundo (Costa \& Bernardes, 2015).

Como resultante dessa concepção hierárquica do cuidado tem-se, por vezes, um dizer e um ouvir incompleto, ou melhor, um não dito, e por conseguinte, a não escuta. Segundo Stanga e Rezer (2015), a adequada concepção de saúde reside em um meio termo entre, o relativismo proposto pela supremacia da subjetividade, e a determinação externa de possibilidades de entendimento proposto pelas concepções universalizadas de saúde como a proposta pela OMS (2006). Proceder à uma definição é tarefa delicada e meticulosa, certamente, segundo os autores, vive-se mais a saúde na prática do que se fala e se discute sobre ela. Impossível deixar de lado é a predominância do discurso fragmentado proposto pela concepção biomédica, essa sim, deve ser vista com olhos atentos pois flerta com o reducionismo típico dos "discursos causal-controlistas e outras construções discursivas relacionadas às experiências vividas de saúde e doença" (Stanga \& Rezer, 2015 p.600)

Para superar o reducionismo discursivo sobre a compreensão causal, objetiva e focal de saúde, é necessário enriquecer o método de escuta da experiência de saúde/doença com um componente hermenêutico que vai produzir um alargamento da escuta, esse componente hermenêutico é a demora, isto é, o alargamento do tempo e da espera para que a escuta hermeneuticamente qualificada aconteça.

De toda sorte, o modelo biomédico ainda se encontra enraizado no discurso predominante, de modo que profissionais da área da saúde continuam a se referir à falta de saúde como oriunda da presença de uma determinada patologia, ou reduzida à um check list sintomático, ou ainda, referemse ao cuidado médico enquanto relacionado ao ato de receitar medicamentos ou de emitir atestados médicos. Todavia, de modo bastante positivo, nos círculos acadêmicos e de produção de conhecimento, tal percepção há muito deixou de ser aceita, sendo o conceito de integralidade e de humanização, as novas cartas coringa da saúde de nossos dias.

\section{(Re) construindo sentidos sobre o cuidado a partir das contribuições da hermenêutica de} H. G. Gadamer.

Ao pensar o tema da assistência e da atenção em saúde, imediatamente nos remetemos à ideia do uso de conhecimento técnico e de tecnologias para o bem estar físico e mental das pessoas. A premissa parece simples: a ciência produz conhecimento sobre a doença, a tecnologia instrumentaliza esse conhecimento e permite a sua aplicação, e por último, os profissionais da saúde aplicam esse conhecimento e esses instrumentos em prol de produzir saúde (Ayres, 2004). Esse entendimento apresenta, contudo, algumas limitações, e essas se relacionam aos aspectos humanos envoltos à esse mesmo contexto (Araújo et al., 2012). É preciso ter clareza que nem todo conhecimento técnico e capacidade instrumental importante para o bem estar pode estar disponível para ser operado naquele momento, e inversamente, mesmo que disponíveis, tais capacidades de intervenção precisam ser ponderadas e limitadas pelas nuances de autonomia daquela pessoa, daquele paciente (Ayres, 2005; Ayres, 2004).

No encontro das subjetividades que emergem no momento assistencial, há sempre alguém que pergunta, mesmo que implicitamente, "o que é bom pra mim?" Como devo ser?", "O que devo fazer?" (Schraiber, 1998). Desse modo, parece correto aferir que uma abordagem assistencial 
cuidadosa deve se distanciar do "objeto de intervenção", para fazer aproximações ao jogo de afetações que ali se concretizam. Isso não quer dizer que a conduta acolhedora e humanizada deve preencher o espaço da boa técnica e da boa instrumentalidade, ou nas palavras de Gadamer (1997), não é o caso da theoría ser substituída pela póiesis, mas sim de enfatizar a práxis, ou a atividade prática que envolve o cuidar para um, e o ser cuidado para o outro. Nesse momento, manifestar-se-ia a phrónesis, a sabedoria prática, uma modalidade de saber que se distancia da percepção de objetos e aproxima-se das relações entre sujeitos (Gadamer, 1997).

A hermenêutica como escuta demorada de um texto, pode, nesse caso, operar em dois níveis: escuta dos discursos sobre saúde/doença e escuta da experiência de saúde/doença. No primeiro caso, propõe para o discurso a questão que interroga sobre a duração da escuta que sustenta o discurso sobre saúde/doença. No segundo caso, propõe à escuta a questão da demora como duração que permitiria à experiência discursar por ela mesma.

Ao tentar reconstruir o cuidado dispensado às relações humanas presentes no momento assistencial, assume-se saúde e doença não apenas como objeto, mas como modos de "ser-nomundo" (Ayres, 2004). Nesse sentido, o poder decisório sobre quais tratamentos escolher e sobre a forma de procedê-los se dará como resultante de um juízo prático, ou seja, com base em uma sabedoria que a mera ciência biomédica desconhece, uma que permite e encoraja a escuta daquilo que o outro, o paciente, espera e deseja como modo de vida.

Dignificar a sabedoria prática no contexto da assistência em saúde soa, em nossos dias, como um desafio. Proceder ao uso dessa sabedoria pressupõe disposição para compreender o presentepassado-futuro da situação que envolve o paciente, e assim reconstruir sentidos e significados sobre a melhor forma de se promover saúde e felicidade à esse paciente (Mello et al., 2017). Significa pois, mobilizar-se e desacomodar-se diante daquilo que merece ser tematizado e repensado (Mello et al., 2017). Esse movimento se dá a partir de um movimento dialético de perguntas e respostas, uma espécie de triangulação entre dois sujeitos e um aspecto, dentro de determinada relação hermenêutica (Gadamer, 1997).

Por vezes ainda, o reconhecimento da dignidade dos conhecimentos práticos pode ser desprezado e então tomado como compreensões obscuras e pouco pensadas (Ayres, 2004). Isso parece ser um equívoco. Um paciente pode, por exemplo, dentro de determinado momento assistencial, expor suas crenças e argumentos. E esses podem, naturalmente, não ser objeto de concordância junto ao profissional da saúde, porém, certamente farão com que esse profissional se aproprie, através de uma escuta atenciosa, da história de vida e das "verdades" daquele paciente. Esse processo pode inclusive tornar mais fácil ao profissional, perfazer o convencimento daquele paciente no que tange à aceitar os métodos e as formas de tratamento, que este pensa ser mais adequado ao caso. Evidentemente, até por conta de seus saberes técnicos, é cabido ao profissional esse tipo de atuação.

A falha relacionada ao processo de cuidado está no desprezo e na não manifestação das subjetividades do paciente. Ao se desconsiderar um saber não-técnico envolvido na questão de saúde ali em pauta, não se estará permitindo que a pessoa assistida participe do próprio cuidado (Araújo, et al., 2012; Ayres; 2004; Schraiber, 1998). Nesse contexto, assimetrias são esperadas e até desejadas (Ayres, 2004), manifestações linguísticas podem ser diferentes, tornando o discurso médico desinteressante à pessoa do paciente. Os sentidos e as dimensões de realidade estão, para a hermenêutica gadameriana, para além da linguagem (Duque, 2003). Tanto que, para Gadamer (1997), a linguagem não está para uma expressão de mundo-em-si, mas sim em uma tentativa de expressar uma visão de mundo. Isso contudo não deve impedir que o profissional compreenda os significados práticos que emergem na alteridade da relação com o paciente e, que a partir disso, possa traduzir de forma humanizada e para linguagem simples as informações técnicas que permeiam o caso.

Trata-se portanto, de proceder à uma tarefa hermenêutica que possibilite o emergir de escolhas por parte do paciente no que tange ao seu próprio tratamento (Caprara, 2003). Para isso, é preciso considerar a historicidade do paciente, seus preconceitos e seus entendimentos a priori (Bonfim, 
2010). Mais do que isso, é preciso uma atitude de enfrentamento pessoal com vistas à autocompreensão, e isso envolve, segundo Gadamer (1997), uma autocrítica perante os próprios preconceitos, para daí, operar em uma atitude de demora perante o paciente.

Segundo Ayres (2004), tem-se no espaço terapêutico uma condição de confiança quase incondicional do paciente para com o seu médico, enfermeiro, psicólogo, etc. Certamente, isso se daria pelo contexto de fragilidade em virtude de algum padecimento de saúde do lado do paciente, todavia, esse fenômeno não deve ser confundido com dependência ou inferioridade em relação ao profissional de saúde (Ayres, 2005; Ayres, 2004; Schraiber, 1998). Nessa esteira, valorizar a sabedoria prática, a phrónesis, parece ser um bom caminho para o início de uma relação terapêutica, e também hermenêutica, humanizada e aberta à troca de palavras, e conseguinte, de experiências entre o profissional e seu paciente.

Em um sistema de saúde pautado pela racionalidade típica das ciências biomédicas, tem-se como regra maior a objetivação do sintoma e a classificação da doença. Diante dos diferentes campos que se propõem a pensar o conceito de saúde, percebe-se não haver consenso (Deluque Júnior \& Costa, 2020), de toda forma, a definição de saúde parece não chamar tanta atenção pela sua presença, quanto a partir da doença (Almeida Filho, 2001). Essa perspectiva é retomada por Gadamer (2011), quando este argumenta em tom critico, contrariamente à definição de saúde que surge a partir do significado de doença.

As normas construídas pelas ciências biomédicas visam combater a doença, pois é na condição de padecimento em virtude dessa, que um sentimento de perigo emergiria e a ajuda terapêutica seria demandada (Gadamer, 2011). Desse modo, fazer-se-ia presente dizer que a prática médica ocidental constrói-se de modo a dominar as manifestações patológicas, e ao mesmo tempo, relegando à segundo plano o interesse quanto ao conceito de saúde, e mesmo à prevenção de doenças (Caprara, 2003). Embota tais modos de operar diante da saúde humana "ocupem lugar fundamental e insubstituível, pelo tanto que já avançaram na tradução de demandas de saúde no plano da corporeidade", ao se atentar para a presença do outro, ou seja, do paciente que demanda por saúde, novos conhecimentos são necessários para que sejam observadas as coisas por uma outra perspectiva (Ayres, 2004 p. 87).

Nesse sentido, conceitos oriundos de áreas como a psicologia, da antropologia, da sociologia, e da filosofia podem ajudar na compreensão das subjetividades envolvidas nas relações terapêuticas que emergem na fenomenalidade da vida cotidiana. Em particular, tais conhecimentos oriundos dessas ciências humanas fazem-se amplamente necessários para a superação da visão individualista que impera nos círculos de saúde (Ayres, 2004). A visão da assistência em saúde consiste, segundo a perspectiva gadameriana, em um misto de ciência e arte, e nesse mesmo contexto, o problema da falta de cuidado se deveria a um suposto esquecimento da dimensão da arte. Haveria muita tecnologia científica nos círculos de saúde contemporâneos (Ayres, 2004), e embora tais tecnologias possam incorporar e expressar a arte médica, por vezes o que se vê é o distanciamento cada vez maior, principalmente nos serviços públicos de atenção à saúde, entre profissionais e pacientes.

Há de compreender-se que, ao tempo em que o espaço terapêutico é, manifestadamente, um espaço de cuidado, é também um espaço de alteridades, onde cada sujeito guarda consigo uma perspectiva ética em ser cuidado pelo outro, principalmente quando esse cuidado não é mais possível sem a ajuda desse outro (Costa \& Bernardes, 2015)

Uma contribuição relevante da hermenêutica gadameriana para o tema do cuidado concentra-se sobre uma ótica que vislumbra os aspectos subjetivos do adoecimento humano (Caprara, 2003). Dentro de uma perspectiva hermenêutica, as pessoas, além de seres biológicos são também sujeitos de sua própria subjetividade, e como tais vivenciam os processos de cura e de cuidado de uma maneira própria e de acordo com suas respectivas subjetividades (Gadamer, 2011). A questão aqui repousa quanto ao modo de se adquirir conhecimentos científicos, e a capacidade para aplicá-los (Caprara, 2003). Para Gadamer (2002; 2011), conhecimentos técnicos são obtidos através do estudo, já a sua correta aplicabilidade, somente será alcançada a partir de um processo 
hermenêutico-experiencial junto à pessoa do outro. A medicina baseada em evidências simplesmente não é, por si só, suficiente para prover um cuidado atencioso e pautado nas peculiaridades subjetivas humanas.

De toda sorte, perceber a pessoa do outro, dentro de seu contexto histórico e subjetivo, parece ser um passo necessário para proceder em um cuidado adequado e humanizado. Há de levar-se em consideração que, de maneira pragmática, isso significa levantar a surrada bandeira da interdisciplinariedade (Ayres, 2004), até por que, segundo a visada da hermenêutica gadameriana, "a racionalidade não pode ser obtida na meditação monológica e solitária de um cientista" (Minayo, 1994 p.59).

Diante disso, faz-se necessário dignificar ciências que, na maioria das vezes são deixadas de fora quando o tema é assistência em saúde. A partir da interação de disciplinas oriundas das chamadas ciências humanas, poder-se-ia construir novos consensos intersubjetivos e instrumentais "orientados a regiões discursivas que se ocupem de experiências coletivas, grupais, culturais, institucionais, ampliando possibilidades de aproximações tecnológicas a essas regiões" (Ayres, 2004 p. 88). A ampliação de conhecimentos interdisciplinares para ponderar sobre uma forma de cuidar que se afaste do ciclo individualista que impera nos serviços de saúde, pode não ser, por si só, suficiente para a construção de uma atitute filosófica de cuidado junto ao outro, porém, é definitivamente um bom começo.

\section{Considerações finais}

Considerado um intelectual de pensamento amplo, Gadamer possui, como ideia central de seus escritos, o processo intelectual que atravessa o homem até a chegada ao ato de compreensão e de entendimento dos fenômenos à sua volta. Tal processo dar-se-ia, principalmente, a partir da interpretação dos fenômenos da linguagem. Para Gadamer (1997), entendimento é interpretação. O cuidado com a saúde e o tratamento médico são regidos pelo conceito de equilíbrio, e nesse sentido, os conhecimentos práticos acerca do cuidado e da saúde não podem, para Gadamer (2011), ser desprezados. Isso significa, para o profissional do cuidado em saúde, ouvir os delineamentos pragmáticos da vida, e da realidade de cada paciente. Nesse sentido, as recomendações curativas devem ir de encontro com o tangível no universo desse paciente.

A partir do ponto de vista da formalidade, o diagnóstico médico é a subordinação de um caso concreto a uma norma geral de saúde ou enfermidade (Costa, 2004). Nesse sentido, a verdadeira arte da medicina se constituiria na definição desse diagnóstico, momento no qual soergueria-se importante tarefa hermenêutica. Diga-se que, através dessa tarefa hermenêutica constituída na forma de um diálogo, atitudes e diretrizes mais humanizadas podem então ser tomadas naquele momento assistencial.

Quando prostrado à situações críticas e estressantes, o ser humano é existencialmente desafiado à questionar a própria vida (Blegen et al., 2016). Confrontar-se com a doença e com o sofrimento o leva, certamente, a um caminho que intenta ao auto-conhecimento por meio do questionamento e da auto-reflexão. Quando a própria condição é insuficiente para cessar o sofrimento, recorre-se ao cuidado de outras pessoas.

Busca-se o cuidado porque dele se necessita, e espera-se que, através dele haja um ato de liberação (Gadamer, 2002; 2011), onde pela fala e pela escuta faça-se cair as máscaras dos velhos preconceitos individuais e, a partir de um ciclo de geração de novos significados, se possa revelar novos saberes na direção de um cuidado humano, acolhedor e atencioso.

A tarefa hermenêutica tem como objetivo fazer gerar novos entendimentos sobre um determinado fenômeno, não como um método a ser seguido, mas como um caminho natural que deve-se fazer inerente ao ser humano dentro de sua caminhada ontológica (Gadamer, 1997). Trata-se de uma atitude filosófica que não é liberta no tempo e no espaço, ocorrendo pois, dentro de uma determinada relação social onde imperam subjetividades e afetações. E é nesse contexto de atravessamentos que o paciente que demanda pelo cuidado se apresenta, na grande maioria das 
vezes, como a parte hipossuficiente de um círculo hermenêutico onde constam, o profissional do cuidado em saúde e ele próprio.

Essa relação contém em seu cerne componentes linguísticos que se alteram mediante o diálogo, onde uma pessoa pode entender sem que tenha sido entendida, e ouvir sem ser ouvida. Desse modo, é papel do profissional da saúde imbuir em seu discurso e em sua escuta, um cuidado que seja atencioso e humanizado. Isso significa, primeiramente, permitir que o paciente se manifeste a respeito de suas crenças e de suas "verdades", para que depois se possa, mediante o que foi atenciosamente ouvido, dizer em palavras simples e cuidadosas o que pensa ser o melhor caminho terapêutico para esse paciente.

Nesse jogo de criação de novos entendimentos, não seria mais do que justo se aquele que possuísse maior arcabouço teórico e pré-disposição interpretativa procedesse no papel de um facilitador da tarefa hermenêutica que é inerente ao outro. De forma prática, isso significa falar a língua do paciente, envolver-se em seus sentidos e significados mais particulares, para que, com base nessa relação dialógica surjam novos entendimentos para ambos intérpretes de um mesmo diálogo. Estar sob tratamento de um profissional da saúde não significa estar sob suas ordens. Uma vez estabelecido um momento assistencial características de abertura e liberdade devem ser concedidas ao paciente para que esse possa, em sua manifestação, tomar decisões à respeito de seu próprio tratamento.

Tal postura implica assumir uma atitude cuidadosa e responsável diante do outro. E nesse sentido, o diálogo parece constituir uma dimensão decisiva para o estabelecimento de uma relação de abertura e igualdade (Costa, 2004), pois sem diálogo não há empatia nem afetação. A partir do diálogo humanizar-se-ia a relação entre profissional da saúde e paciente, movimento fundamental para a cura e para o re-estabelecimento da saúde desse paciente. Uma atitude autoritária que flerte com o desprezo das opiniões e argumentos do leigo, prejudica a capacidade de cuidar e, em uma última instância, acaba por negar o "outro". Eis o momento patológico da atenção e do cuidado em saúde.

\section{Referências bibliográficas}

Almeida Filho, Naomar de. (2001) For a general theory of health: Preliminary epistemological and anthropological notes. Cadernos de Saúde Pública, Vol. 17 Brasil (Pp. 753-799). DOI: https://dx.doi.org/10.1590/s0102-311x2001000400002

Araújo, Janieiry Lima de; Paz, Elizabete Pimenta Araújo; Moreira, Thereza Maria Magalhães. (2012) Hermenêutica e saúde: reflexões sobre o pensamento de Hans-Georg Gadamer. Revista da Escola de Enfermagem da USP, Vol. 46 No 1. Brasil. (Pp. 200-207). DOI: https://dx.doi.org/10.1590/S0080-62342012000100027

Ayres, José Ricardo de Carvalho Mesquita. (2004) Cuidado e reconstrução das práticas de saúde. Interface. Vol. 8, No 14. Brasil. (Pp. 73-92). DOI: https://dx.doi.org/10.1590/S141432832004000100005

Ayres, José Ricardo de Carvalho Mesquita. (2005) Hermenêutica e humanização das práticas de saúde. Ciência \& Saúde Coletiva. Vol. 10, No 3. Brasil. (Pp. 549-560). DOI: https://dx.doi.org/10.1590/S1413-81232005000300013

Ayres, José Ricardo de Carvalho Mesquita. (2007) Uma concepção hermenêutica de saúde. Physis. Vol. 17, No 1. Brasil (Pp. 43-62). DOI: https://dx.doi.org/10.1590/s010373312007000100004

Barros, Márcia Maria Mont' Alverne de; Jorge, Maria Salete Bessa; Pinto, Antonio Germane Alves. (2010) Prática de saúde mental na rede de atenção psicossocial: a produção do cuidado e as tecnologias das relações no discurso do sujeito coletivo. Rev. APS. Vol. 13, No 1. Brasil. (Pp. 72-83). Disponível em https://periodicos.ufjf.br/index.php/aps/article/view/14362 Consulta 05/01/2020. 
Benevides, Regina; Passos Eduardo. (2005) Humanização na saúde: um novo modismo? Interface Vol. 9, $\mathrm{N}^{\mathrm{o}}$ 17. Brasil. (Pp. 389-94). DOI: https://dx.doi.org/10.1590/S141432832005000200014

Bettinelli, Luiz Antonio; Wasklevicz, Josemara; Erdmann, Alacoque Lorenzini. (2003) Humanização do cuidado no ambiente hospitalar. In: Pessini L \& Bertachini L (orgs.). Humanização e cuidados paliativos. EDUNISC - Ediç,oes Loyola. Brasil. Pp. (87100).

Blegen, Nina Elisabeth; Eriksson, Katie; Bondas, Terese. (2016) Ask Me What Is in My Heart of Hearts! The Core Question of Care in Relation to Parents Who Are Patients in a Psychiatric Care Context. International Journal of Qualitative Studies on Health and Well-Being. $\quad$ Vol. $11 . \quad$ Noruega. $\quad$ (P. DOI: https://dx.doi.org/10.3402/qhw.v11.30758

Boff, Leonardo. (1999) Saber cuidar: ética do humano, compaixão pela terra. Vozes. Brasil.

Bonfim, Vinicius Silva. (2010) Gadamer e a experiência hermenêutica. Revista CEJ. Vol. 14 N $^{\circ}$ 49. Brasil. (Pp. 76-82). Disponível em https://revistacej.cjf.jus.br/revcej/article/view/1152 Consulta 03/01/2020.

Brêtas, Ana Cristina Passarela. (2003) Cuidadores de idosos e o sistema único de saúde. Rev. bras. enferm. Brasília, Vol. 56, $\mathrm{N}^{\circ} \quad 3$. Brasil. (Pp. 298-301). DOI: https://dx.doi.org/10.1590/S0034-71672003000300016

Caprara, Andrea. (2003) Uma abordagem hermenêutica da relação saúde-doença. Cad. Saúde Pública. Vol. 19, No 4. Brasil. (Pp. 923-931). DOI: https://dx.doi.org/10.1590/S0102311X2003000400015

Cavalcante, Cinthia Mendonça; Pinto, Diego Muniz; Carvalho, Ana Zaiz Teixeira de; Jorge, Maria Salete Bessa; Freitas, Consuelo Helena Aires de. (2011) Desafios do cuidado em saúde mental na estratégia saúde da família. Revista Brasileira em Promoção da Saúde. Vol. 2, No 24. Brasil. (Pp. 102-108). DOI: https://dx.doi.org/10.5020/18061230.2011.p102

Corbani, Nilza Maria de Souza; Brêtas, Ana Cristina Passarela; Matheus, Maria Clara Cassuli. (2009) Humanization of nursing care: what is it? Rev Bras Enferm. Vol. 4, No 62, Brasil. (Pp. 349-54). DOI: https://dx.doi.org/10.1590/S0034-71672009000300003

Correia, Edgar. (2006) Uma visão fenomenológica-existencial em psicologia da saúde?!. Aná. Psicológica. Vol. 24, $\mathrm{N}^{\circ}$ 3. Portugal. (Pp. 337-341). Disponível em: http://www.scielo.mec.pt/scielo.php?script=sci_arttext\&pid=S0870$82312006000300007 \& \operatorname{lng}=$ pt\&nrm=iso Consulta 22/12/2019.

Costa, Ana Maria. (2004) Integralidade na atenção e no cuidado a saúde. Saude soc. Vol. 13, No 3. Brasil. (Pp. 5-15). DOI: https://dx.doi.org/10.1590/S0104-12902004000300002

Costa, Márcio Luís; Bernardes, Anita Guazzelli. (2013) Práticas docentes e enfrentamentos: de um modelo de intervenção a um modelo de cuidado. Série-Estudos. No 35. Brasil. (Pp. 157172). Disponível em: https://www.serie-estudos.ucdb.br/serie-estudos/article/view/28 Consulta 10/12/2019.

Costa, Márcio Luís; Bernardes, Anita Guazzelli. (2015) El cuidado en la educación del profesional de la salud: Educar para cuidar. Revista Mexicana de Psicología. Vol. 32, N². México. (Pp. 190-198). Disponível em: https://www.redalyc.org/pdf/2430/243045364009.pdf Consulta 10/12/2019.

Deluque Júnior, Romano; Costa, Márcio Luís. (2020). Mídia, Preconceito e Adoecimento Mental: Contribuições da Hermenêutica Gadameriana - Um Ensaio a partir da obra 'Verdade e Método"de Hans-Georg Gadamer. Revista Comunicação, Cultura e Sociedade, Vol. 10, $\quad \mathrm{N}^{\mathrm{o}}$ 2. Brasil. (Pp. 051-078). Disponível em: https://periodicos.unemat.br/index.php/ccs/article/view/4430 Consulta 10/02/2020.

Duque, João. (2003) Da hermenêutica dos limites aos limites da hermenêutica: para uma leitura crítica de Gadamer. In: Reimão, Cassiano (Org.). H.-G. Gadamer: experiência, linguagem e interpretação. Lisboa: Universidade Católica. (p. 78). Portugal. 
Fortes, Antônio de Carvalho; Martins, Cleide de Lavieri. (2000) A ética, a humanização e a saúde da família. Rev. bras. enferma. Brasil. Vol. 53, $\mathrm{N}^{\circ}$ Especial. (Pp. 31-33). DOI: https://dx.doi.org/10.1590/S0034-71672000000700005

Gadamer, Hans-Georg. (1997) Verdade e método - Traços fundamentais de uma hermenêutica filosófica. Tradução Flávio Paulo Meurer. 3. ed. Vozes. Brasil.

Gadamer, Hans-Georg. (2002) Mistério da saúde. In: Gadamer, Hans-Georg (2002) O mistério da saúde: o cuidado da saúde e a arte da medicina. Edições 70 . Portugal.

Gadamer, Hans-Georg. (2011) O Caráter oculto da saúde. Vozes. Brasil.

Gomes, Eduardo Tavares; Brandão, Brígida Maria Gonçalves de Melo; Abrão, Fátima Maria da Silva; Bezerra, Simone Maria Muniz da Silva. (2019) Contributions by Leonardo Boff for the understanding of care. Journal of Nursing UFPE on line. Vol. 12, $\mathrm{N}^{\circ}$ 2. Brasil. (Pp. 531-536). DOI: https://doi.org/10.5205/1981-8963-v12i2a23563p531-536-2018

Macedo, Lilian Magda de; \& Martins, Sueli Terezinha Ferrero. (2014) Interdependência entre os níveis de atenção do Sistema Único de Saúde (SUS): significado de integralidade apresentado por trabalhadores da Atenção Primária. Interface (Botucatu). Vol. 18, N 51. Brasil. (Pp. 647-60). DOI: https://dx.doi.org/10.1590/1807-57622013.0597

Matos, Valéria Christine Albuquerque de Sá; Silva Júnior, Almir Ferreira. (2017) Reflexões da hermenêutica filosófica para a prática do psicólogo em contexto hospitalar. Revista da Abordagem Gestáltica. Vol. 23, No 1. Brasil. (Pp. 84-94). Disponível em: http://pepsic.bvsalud.org/scielo.php?script=sci_abstract\&pid=S180968672017000100010\&lng=pt\&nrm=iso Consulta 28/11/2019.

Mello, Débora Falleiros de; Silva, Rosane Meire Munhak da; Pancieri, Letícia. (2017) Êxito técnico e sucesso prático em visita domiciliar para o cuidado da saúde da criança. Revista Pesquisa Qualitativa. Vol. 5. Brasil. (Pp. 13-22). Disponível em: http:// rpq.revista.sepq.org.br/index.php/rpq/article/view/46/60 Consulta 15/11/1019.

Minayo, Maria Cecília de Souza. (1988) Saúde-doença: uma concepção popular da etiologia. Cad. Saúde Pública. Vol. 4, $\mathrm{N}^{\circ} \quad$ 4. Brasil. (Pp. 363-381). DOI: https://dx.doi.org/10.1590/S0102-311X1988000400003

Minayo, Maria Cecília de Souza. (1994) Interdisciplinaridade: funcionalidade ou utopia? Saúde e Sociedade. Vol. 3, No 2. Brasil. (Pp. 42-63). DOI: https://dx.doi.org/10.1590/S010412901994000200004

OMS - Organización Mundial de la Salud. (2006) Constitución de la Organización Mundial de la Salud. [Internet]. Disponível em: http://www.who.int/governance/eb/who_constitution_sp.pdf Consulta 15/11/1019.

Pereira, Thomé Seni Oliveira; Barros, Monalisa Nascimento dos Santos; Augusto, Maria Cecília Nobrega de Almeida. (2011) O Cuidado em Saúde: o Paradigma Biopsicossocial e a Subjetividade em Foco. Mental. Vol. 9, No 17. Brasil. (Pp. 523-36). Disponível em: http://pepsic.bvsalud.org/pdf/mental/v9n17/02.pdf Consulta 23/12/2019.

Pessini, Léo. (2000) Humanização da dor e sofrimento humanos no contexto hospitalar. Bioética. Conselho Federal de Medicina. Vol. 10, No 2. Brasil.

Rillo, Arturo. (2008) Aproximación ontológica al sentido originario de la salud desde la hermenéutica filosófica. Rev Hum Med. Vol. 8, № 1. México. (Pp. 0-0). Disponível em: https://www.researchgate.net/publication/262501148_Aproximacion_ontologica_al_s entido_originario_de_la_salud_desde_la_hermeneutica_filosofica_Consulta 21/12/2019.

Rillo, Arturo. (2015) Análisis hermenéutico de la pregunta por la salud. Rev Hum Med. Vol.15, $N^{o} \quad 3 . \quad$ México. (Pp. 401-420). Disponível em: https://pesquisa.bvsalud.org/portal/resource/pt/lil-769357 Consulta 21/12/2019. 
Schraiber, Lilia Blima. (1998) Medicina tecnológica e prática profissional contemporânea: novos desafios, outros dilemas. Interface (Botucatu). Vol. 2, No 2. Brasil. (Pp. 215-216). DOI: 10.1590/S1414-32831998000100020

Silva Rafael Celestino da; Ferreira, Márcia de Assunção. (2013) The practice of intensive care nursing: alliance among technique, technology and humanization. Revista da Escola de Enfermagem da USP. Vol. 47, $\mathrm{N}^{\mathrm{o}}$ 6. Brasil. (Pp. 1324-1331). DOI: https://dx.doi.org/10.1590/S0080-623420130000600011

Silva, Kênia Lara; Sena, Roseni Rosângela de. (2008) Integralidade do cuidado na saúde: indicações a partir da formação do enfermeiro. Revista da Escola de Enfermagem da USP. Vol. 42, $\quad \mathrm{N}^{\mathrm{o}}$ 1. Brasil. (Pp. 48-56). DOI: https://dx.doi.org/10.1590/S008062342008000100007

Spence, Deborah Gail. (2001) Hermeneutic notions illuminate cross-cultural nursing experiences. Journal of Advanced Nursing. Vol. 35. Nova Zelândia. (Pp. 624-630). DOI Http: https://dx.doi.org/10.1046/j.1365-2648.2001.01879.x

Spence, Deborah Gail. (2017) Supervising for Robust Hermeneutic Phenomenology: Reflexive Engagement Within Horizons of Understanding. Qualitative Health Research. Vol. 10. Nova Zelândia. (Pp.971-980). DOI: https://dx.doi.org/10.1177\%2F1049732316637824

Stanga, Adriani Cristiani; Rezer, Ricardo. (2015) Concepções de saúde, trabalho docente e o PróSaúde: nos caminhos da hermenêutica. Physis: Revista de Saúde Coletiva. Vol. 25, $N^{0}$ 2. Brasil. (Pp. 593-614). DOI: https://dx.doi.org/10.1590/S0103-73312015000200014

Valerius, Jukka. (2003) Autonomy, Subject-relativity, and Subjective and Objective Theories of Well-being in Bioethics. Theoretical Medicine Vol. 24, No 5. Finlândia. (Pp.363-379). DOI: https://dx.doi.org/10.1023/b:meta.0000006908.26112.fe 